\title{
Optimization of Hydrogen Jet Configuration by Single Hole Nozzle and High Speed Laser Shadowgraphy in High Pressure Direct Injection Hydrogen Engines
}

\author{
Masakuni Oikawa) $^{1)}$ Yusuke Ogasawara $^{2)}$ Yoshikazu Kondo $^{3)}$ Kanan Sekine ${ }^{4)}$ \\ Yasuo Takagi ${ }^{5)}$ Yoshio Sato ${ }^{6)}$ \\ 1)-4) Tokyo City University Graduate School \\ 1-28-1 Tamazutsumi, Setagaya-ku, Tokyo, 158-8557, Japan (E-mail: g0991901@tcu.ac.jp) \\ 5) Tokyo City University \\ 1-28-1 Tamazutsumi, Setagaya-ku, Tokyo, 158-8557, Japan \\ 6) National Traffic Safety and Environment Laboratory \\ 7-42-27 Jindaiji-higashi, Chofu-shi, Tokyo 182-0012, Japan
}

Received on September 15, 2011

Presented at the JSAE/SAE International Powertrains,Fuels \& Lubricants on September 1, 2011

\begin{abstract}
A new ignition-combustion concept named PCC (Plume Ignition Combustion Concept), which ignite rich mixture plume in the middle of injection period or right after injection of hydrogen is completed, is proposed by the authors in order to reduce NOx emissions in high engine load conditions with minimizing trade-offs on thermal efficiency. In this study fundamental requirements of hydrogen jet and ignition timing to optimize PCC performance are investigated by using single and multi-hole nozzle with a combination of high speed laser shadowgraphy to visualize propagating flame. As a result, it was infered that igniting the mixture plume in the middle of injection period with minimizing jet penetration to chamber wall is effective reducing NOx formation even further.
\end{abstract}

KEY WORDS: (Standardized) heat engine, spark ignition engine, performance/fuel economy/efficiency, (Free) Hydrogen, Shadowgraph, Plume Combustion [A1]

\section{Introduction}

In a middle of continually growing societal concerns about environmental and energy issues, research is under way in many quarters on hydrogen engines that have no carbon dioxide $\left(\mathrm{CO}_{2}\right)$ in their exhaust and can be operated on a renewable energy source (1)(2). A direct-injection hydrogen engine (DI hydrogen engine) in particular provides higher power output by increasing charging efficiency and avoiding the occurrence of backfire, which are weak points of port injected hydrogen engines. Further more, chacteristics of DI hydrogen engin, such as performance, efficiency, and emissions ${ }^{(3)}$, improved thermal efficiency by optimizing the fuel injection pressure and timing and the ignition timing ${ }^{(4)}$, and process of mixture formation ${ }^{(5)(6)}$, had beed investigated. However, majour subject of tremendous increase in nitrogen oxide (NOx) emissions that occurs during high-output operation has been left unsolved.

To date, the authers have proposed a new combustion process called the Plume Ignition Combustion Concept $(\mathrm{PCC})^{(7)(8)}$, in whch with an optimal combination of hydrogen injection timing and ignition timing, the plume tail of the hydrogen jet is spark-ignited upon the completion of fuel injection to accomplish combustion of a rich mixture. This PCC combustion process markedly reduces NOx emissions in the high-output region while maintaining high levels of thermal efficiency and power. Moreover, test results confirm the potential of PCC combustion for reducing NOx emissions to a level complying with Japan's 2009 exhaust emission regulations for heavy-duty vehicle engines by using exhaust gas recirculation (EGR) alone without applying any exhaust aftertreatment system ${ }^{(9)}$. However, the details of the conditions required for viable PCC combustion leading to a substantial reduction in NOx emissions are still not clear.

The objectives of the present study are to make clear the conditions required of the hydrogen jet in the PCC combustion process expanding ignition timing to the middle of injection duration in order to achieve higher thermal efficiency and reduced NOx emissions further. Single-hole injectors with a simply shaped nozzle hole were used to investigate the required hydrogen jet conditions. In addition, a laser shadowgraphy method was used to visualize the propagation of the hydrogen combustion flame in the combustion chamber in order to make clear the condition of the hydrogen jet and flame propagation.

\section{Experimental Equipment and Procedure}

\subsection{Test engine}

A single-cylinder test engine that main specification is given in Table 1 is used in the experiments. Figure 1 shows the combustion chamber configuration, arrangement of the injector nozzle and the spark plug. The combustion chamber had a bowl that was formed in the piston. The injector nozzle machined in a 
nozzle cap was oriented such that the hydrogen jet was aimed at the piston bowl when the piston was at top dead center. Seven single-hole nozzles having hole diameters of 1.7, 2.0, 2.3, 2.9, 4.0, 4.5 and $5.0 \mathrm{~mm}$ and one multi-hole nozzle with nine holes of 1.3 $\mathrm{mm}$ in diameter were used in the experiments ${ }^{(7)(9)}$. Spark plug was positioned $20 \mathrm{~mm}$ from the injector nozzle hole.

The hydrogen concentration in the exhaust gas was measured with a magnetic sector type hydrogen gas analyzer (MSHA$1000 \mathrm{~W}$, Horiba, Ltd.) in addition to other exhaust gas components which are measured with an automobile exhaust gas analyzer. The combustion characteristics were analyzed with a combustion analyzer (DS-9110, Ono Sokki Co., Ltd.) by using cylinder pressure measured with a piezoelectric pressure sensor.

In order to conduct combustion visualization experiments, the combustion chamber configuration of the test engine was modified, by introducing an extended piston having quartz window on the bottom of piston bowl as is shown in Fig.2, through which inside of the combustion chamber was visualized from the bottom of the piston bowl. Surface of the cylinder head wall, intake/exhaust valve head and the adapter for attaching the fuel injector were surface treated to a mirror-finish, thereby forming a reflective optical system. An argon ion laser (Stabilite 2017, Spectra-Physics) was used as the light source, and a digital high-speed video camera (Fastcam SA1.1, Photron, Ltd.) was used to take photographs.

\subsection{High-pressure injector}

A high-pressure injector developed in-house at our university $^{(1)}$ was used to inject hydrogen fuel directly into the cylinder. The injector nozzle was of the hole type and the nozzle hole diameter was varied in the experiments as noted earlier. The specifications of the high-pressure injector system are given in Table 2. The needle valve of this common rail injector is driven by oil pressure, enabling hydrogen to be injected at the maximum pressures up to $20 \mathrm{MPa}$ and providing fast response, including facilitating multiple-stage injection. This injector system is capable of injecting the maximum required fuel quantity into the combustion chamber during injection duration of 30 crank angle (CA) degrees at an engine speed of $3000 \mathrm{rpm}$. The injection timing and duration are adjusted by controlling timing and quantity of spill oil in common rail injector drive line.

\subsection{Combustion analysis}

\subsubsection{Cooling loss index}

The actual cooling loss in the cylinder $\mathrm{Q}_{\mathrm{Wth}}$ is defined as a difference between produced heat by combustion $\mathrm{Q}_{\mathrm{u}}$ which is subtracted heating value of unburned fuel in the cylinder $\mathrm{Q}_{\mathrm{ub}}$ from supplied heating value of fuel $\mathrm{Q}_{\text {fuel }}$ and nominal released heat $\mathrm{Q}_{\mathrm{RH}}$ which is calculated from the cylinder pressure as is shown in equation (1). Because $\mathrm{Q}_{\mathrm{ub}}$ is not measured in this study, however, heating value of unburned hydrogen in exhaust gas $\mathrm{Q}_{\mathrm{H} 2 \mathrm{em}}$ is used instead to represent cooling loss level in the cylinder, defining new term cooling loss index $\Phi_{\mathrm{w}}$ which is shown in equation (2).

$$
Q_{\text {Wth }}=Q_{u}-Q_{R H}=Q_{\text {fuel }}-Q_{u b}-Q_{R H}
$$

Table 1 Specifications of single cylinder engine

\begin{tabular}{ll}
\hline Item & Specification \\
\hline Engine Displacement & $1054 \mathrm{~mL}$ \\
Bore x Stroke & $108 \mathrm{~mm}$ x $115 \mathrm{~mm}$ \\
Combustion Chamber & Bowl \\
No. of Valves & 2 Valves \\
Aspiration & NA \\
Cooling System & Water Cooled \\
Compression Ratio & $13: 1$ \\
Swirl ratio & 2.2 \\
Ignition system & Spark Ignition \\
\hline
\end{tabular}

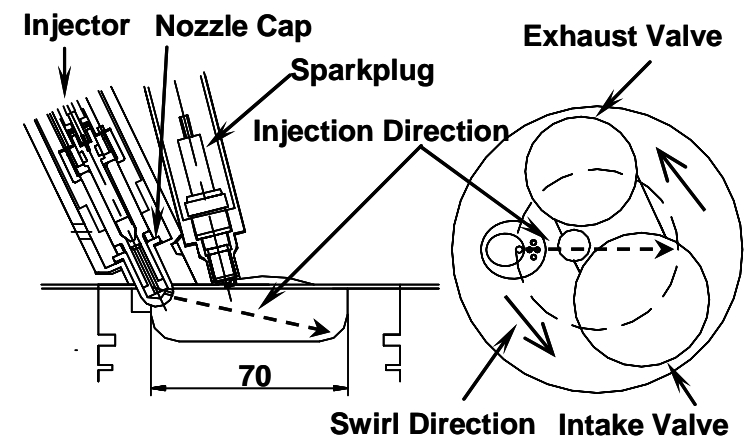

Fig. 1 Combustion chamber configuration of the DI single cylinder engine

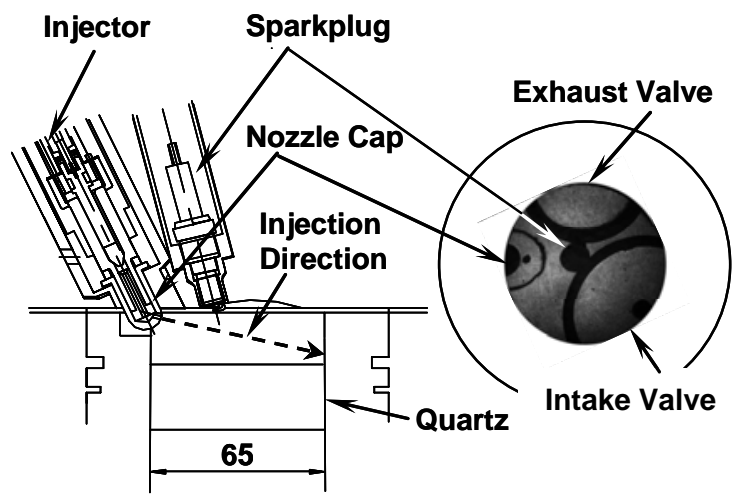

Fig. 2 Combustion chamber configuration of the DI single cylinder optical engine

Table 2 Specifications of high pressure injector

\begin{tabular}{|c|c|}
\hline Items & Specification \\
\hline Nozzle Type & Hole Nozzle \\
\hline Drive Method & $\begin{array}{l}\text { Oil Pressure Driven \& } \\
\text { Back Pressure Spill Control }\end{array}$ \\
\hline Max. Oil Pressure & $120 \mathrm{MPa}$ \\
\hline Max. Inj. Pressure & $20 \mathrm{MPa}$ \\
\hline $\begin{array}{l}\text { Max. Inj. Rate } \\
\text { ( Target ) }\end{array}$ & $\begin{array}{l}400 \text { Nml / stroke } \\
\text { @30 deg CA.3000 rpm }\end{array}$ \\
\hline
\end{tabular}

\subsubsection{Calculation of the coefficient of variation of IMEP}

The cycle-by-cycle variation in the combustion stability of an engine can be expressed by the coefficient of variation of the indicated mean effective pressure COV calculated with Eq. (3). in 
which standard deviation of the indicated mean effective pressure (IMEP) $\sigma_{\text {IMEP }}$ is divided by the average of IMEP $\bar{P}_{\text {IMEP }}$.

$$
C O V=\frac{\sigma_{I M E P}}{\bar{P}_{I M E P}}
$$

\subsection{Experimental procedure}

Experiment was carried out under the constant IMEP of 0.85 $\mathrm{MPa}$ which was wide open throttling (WOT) representing highload conditions, engine speed of $1000 \mathrm{rpm}$. Excess air ratio $\lambda$ ranged between 1.5 and 1.8. In shadowgraphic visualization experiment, $\lambda$ was increased to around 2.7 in order to prevent the bottom view engine system from mechanical damage under engine speed of $1000 \mathrm{rpm}$.

\section{Experimental Results and Discussions}

3.1. Characteristics of injection timing of PCC combustion with a single-hole nozzle

The combustion characteristics obtained with two singlehole nozzles, having hole diameters of $2.3 \mathrm{~mm}$ and $4.0 \mathrm{~mm}$, are shown in Fig. 3 in relation to the start of injection (SOI) as representative examples of single-hole nozzle. The ignition timing was set to the minimum advance for the best torque (MBT) in each injection timing. The results are compared with those obtained with a multi-hole nozzle, which has been used in previous studies and has nine holes of $1.3 \mathrm{~mm}$ in diameter arranged in a horizontal plane. The data for the single-hole nozzles indicate that the high nitrogen oxide (NOx) concentration seen for an early injection timing in the first half of the compression stroke was substantially reduced by retarding the SOI to a late injection timing in the latter half of the stroke near top dead center. This result will be described in detail in the next section.

With the retarded SOI, the mixture plume was ignited right after the end of injection (EOI) and offered the MBT, enabling PCC combustion to be achieved even with the single-hole nozzles,

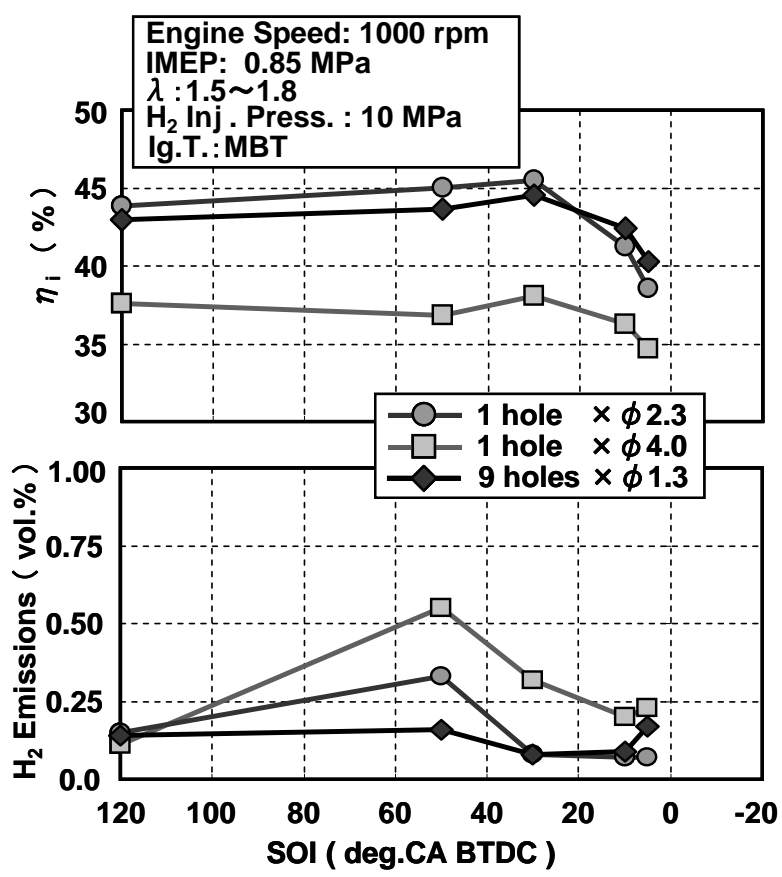

as it was with the multi-hole nozzle, and resulted in a substantial NOx reduction. As described elsewhere concerning the details of PCC combustion, it is assumed that the rich mixture plume burns right after EOI under the effects of a strong disturbance and the high diffusion characteristic of hydrogen, thereby suppressing the formation of NOx. The results in Fig. 3 confirmed that stable combustion was accomplished near MBT with both single-hole nozzles without any pronounced increase in unburned hydrogen and COV (not shown in the figure). However, it is observed that thermal efficiency and the NOx emission level differed between the two nozzle hole diameters. That difference is presumably attributable to a difference in the mixture state in the combustion chamber owing to a difference in the shape of the injected hydrogen jet.

\subsection{Effect of the hole diameter of single-hole nozzles on PCC combustion at MBT}

Fig. 4 shows the effect of the nozzle hole diameter of the single-hole nozzles on engine performance under PCC combustion conditions and the ignition timing at MBT. The data in the figure show discontinuous characteristics for $\mathrm{NOx}$ emissions and the quantity of unburned hydrogen that fall into two groups-a group of small nozzle hole diameters from 1.7 to 2.3 $\mathrm{mm}$ and a group of large nozzle hole diameters from 2.9 to 5.0 $\mathrm{mm}$. Therefore, engine performance will be discussed here with respect to these two groups of nozzle hole diameters.

\subsubsection{PCC combustion characteristics for small nozzle hole diameter group (1.7-2.3 mm)}

Characteristic seen for the small nozzle hole diameter group is the high level of NOx emissions and the low level of unburned hydrogen. This is thought to be caused by increased jet velocity with small hole diameter nozzle in hole type injector. As is indicated in the right-lower figure of Fig.3, different nozzle hole diameter offered almost the same injection duration for the same injected hydrogen amount during PCC condition. This means velocity of jet is increased as a nature of the injector used in this study which has sack volume between injector valve seat and nozzle hole. Therefore it is inferred that with the small hole
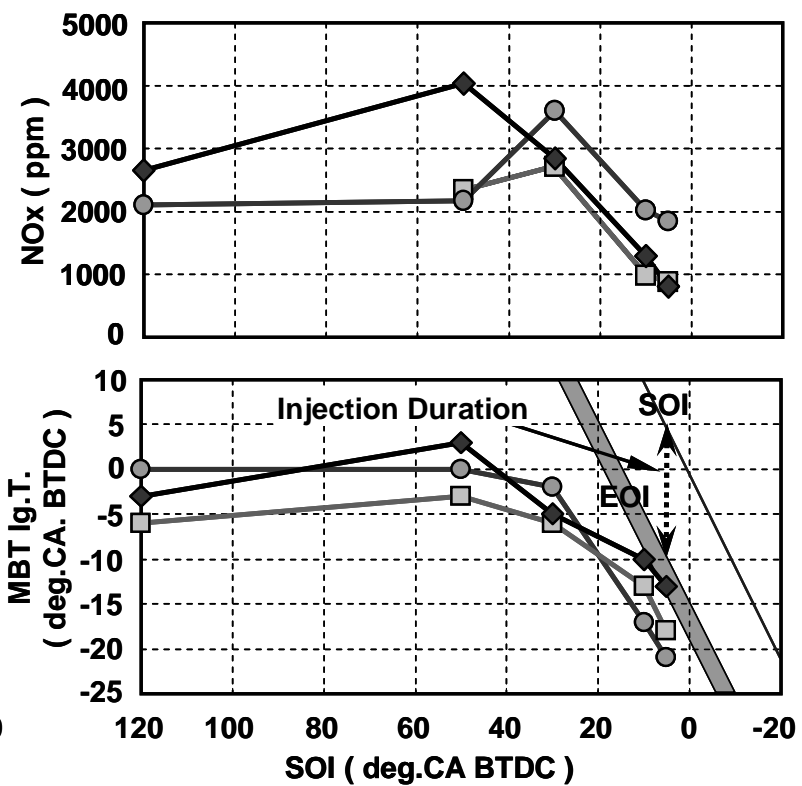

Fig. 3 Effect of injection timing on engine performance by single-hole nozzle (Comparison with multi-hole nozzle) 

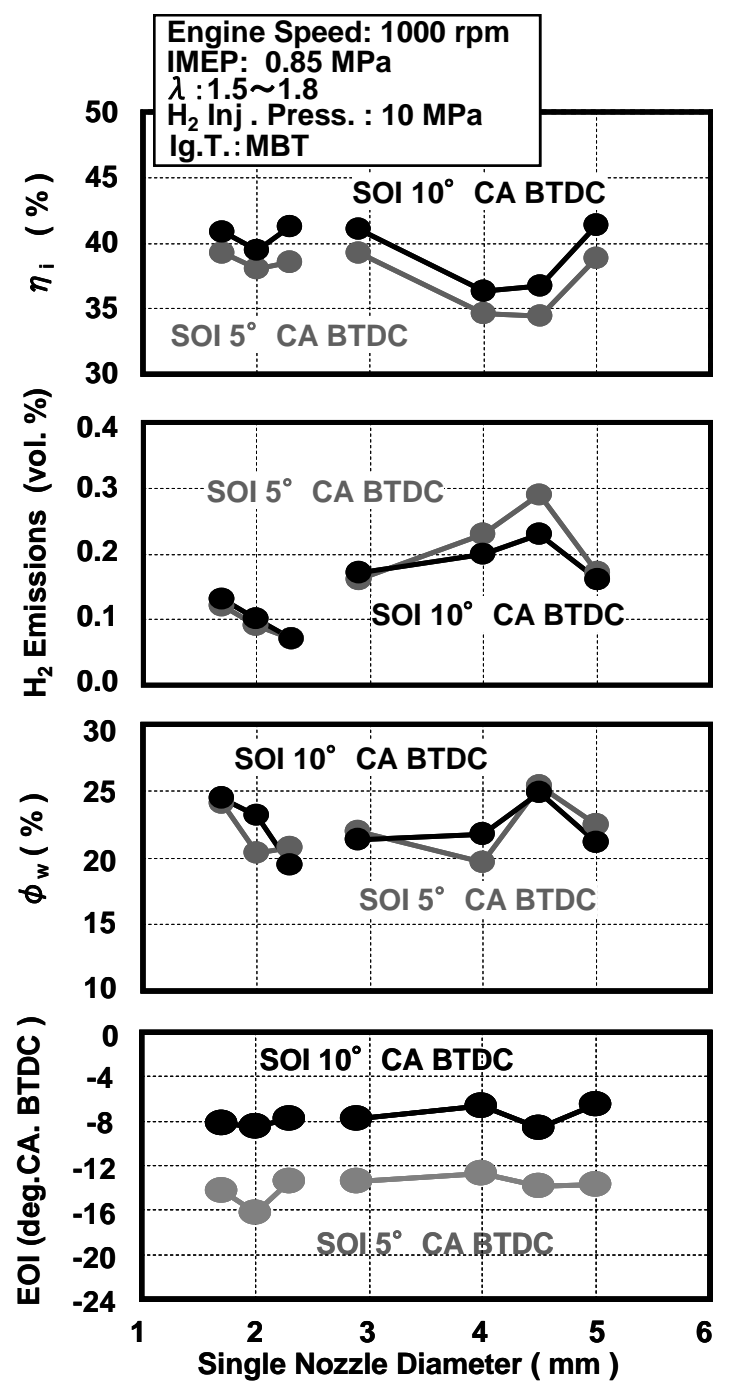
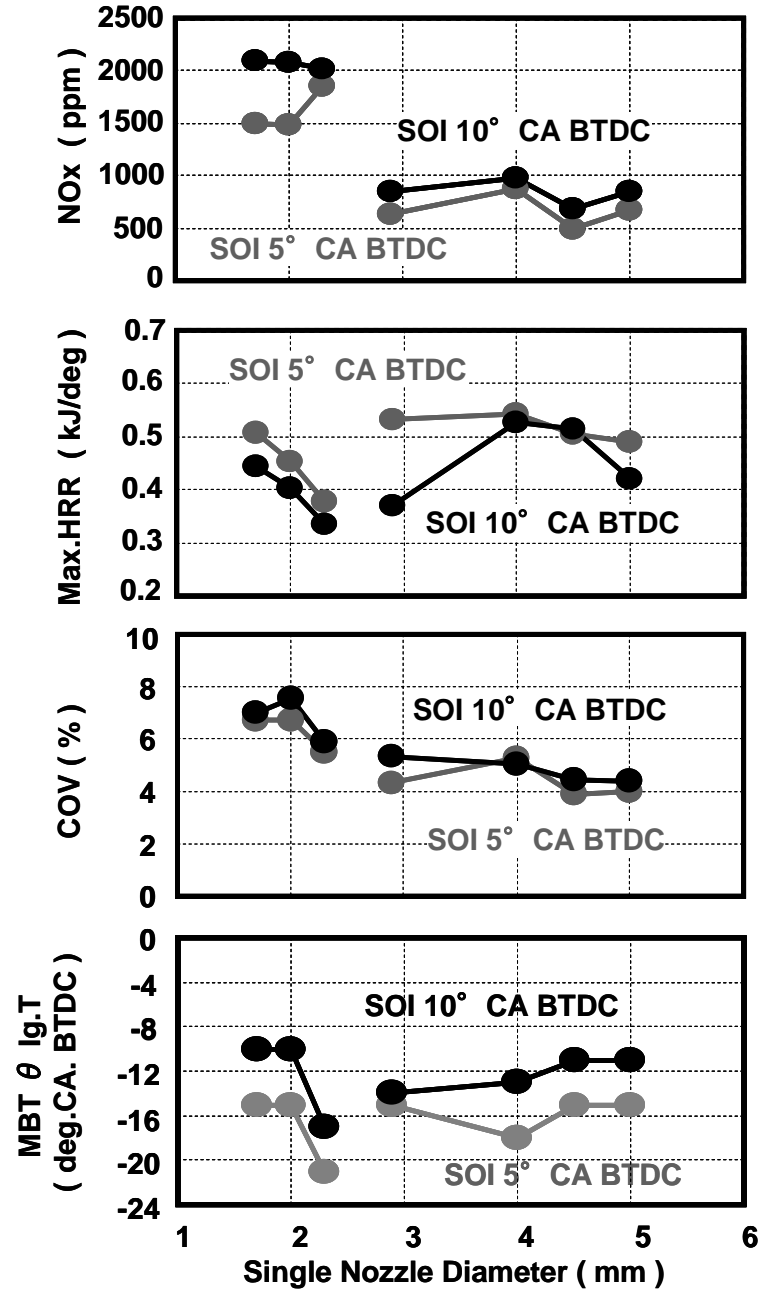

Fig. 4 Effect of nozzle diameter on PCC performance for single-hole nozzles

diameters from 1.7 to $2.3 \mathrm{~mm}$, the high flow velocity of the hydrogen jet enhanced entrainment of surrounding air, thereby promoting mixture formation and leading to higher NOx emissions and lower unburned hydrogen.

\subsubsection{PCC combustion characteristics for large nozzle hole} diameter group (2.9-5.0 mm)

One characteristic seen for the large nozzle hole diameter group is the low level of NOx emissions. It is inferred that NOx formation was suppressed because mixing of the fuel and air did not proceed well owing to the low flow velocity of the hydrogen jet, which was the opposite of the case for the small nozzle hole diameter group. As a result, local mixture homogeneity was not promoted within the mixture plume, thereby increasing unburned hydrogen and lowering the indicated thermal efficiency. However the NOx emissions hardly decline with increase of hole-diameter in the group. This suggests that additional factor concerning NOx formation is included in the result for increased hole diameterin a large nozzle hole diameter group, remaining as a research issue in the future. The cooling loss in this group shows almost the same level as that in the small nozzle diameter group. However, it tends to increase by the increased nozzle hole diameter. This is inferred that flame propagation of locally high heterogeneous mixture created by larger nozzle hole diameter shows eccentrical geometry because of low local mixture homogeneity and increases local burning in the vicinity of combustion chamber wall ${ }^{(10)}$ even in the ignition timing right after completion of injection. The increase in cooling loss is one of factors which decrease thermal efficiency. The peak heat release rate was higher than that of the small nozzle hole diameter group. That was probably due to combustion of a richer mixture plume because of less mixing of the hydrogen and air. These results indicate that increasing the nozzle hole diameter works not to entrain the air in hydrogen mixture plume results in faster combustion and also works to suppress NOx formation.

\subsection{PCC combustion characteristics relative to ignition timing}

\subsubsection{Reduction of NOx igniting during the injection period}

Fig. 5 shows the effect of ignition timing of engine performance under WOT condition, in which nozzle hole used was one of the single-hole nozzle with a diameter of $2.3 \mathrm{~mm}$ and a multi-hole nozzle with nine $1.3-\mathrm{mm}$ diameter. The SOI was set at 10 deg.CA BTDC. Only ignition timing was varied after IMEP was set to $0.85 \mathrm{MPa}$ at the MBT. Here after ignition timing during the injection period is named as mid-injection-ignition PCC and that after the end of injection is named post-injection-ignition PCC, respectively. Most of the MBT ignition timing which performance was mentioned in the previous section belongs to the post-inj.-ig. PCC. The mid-inj.-ig. PCC, reduced NOx formation, 

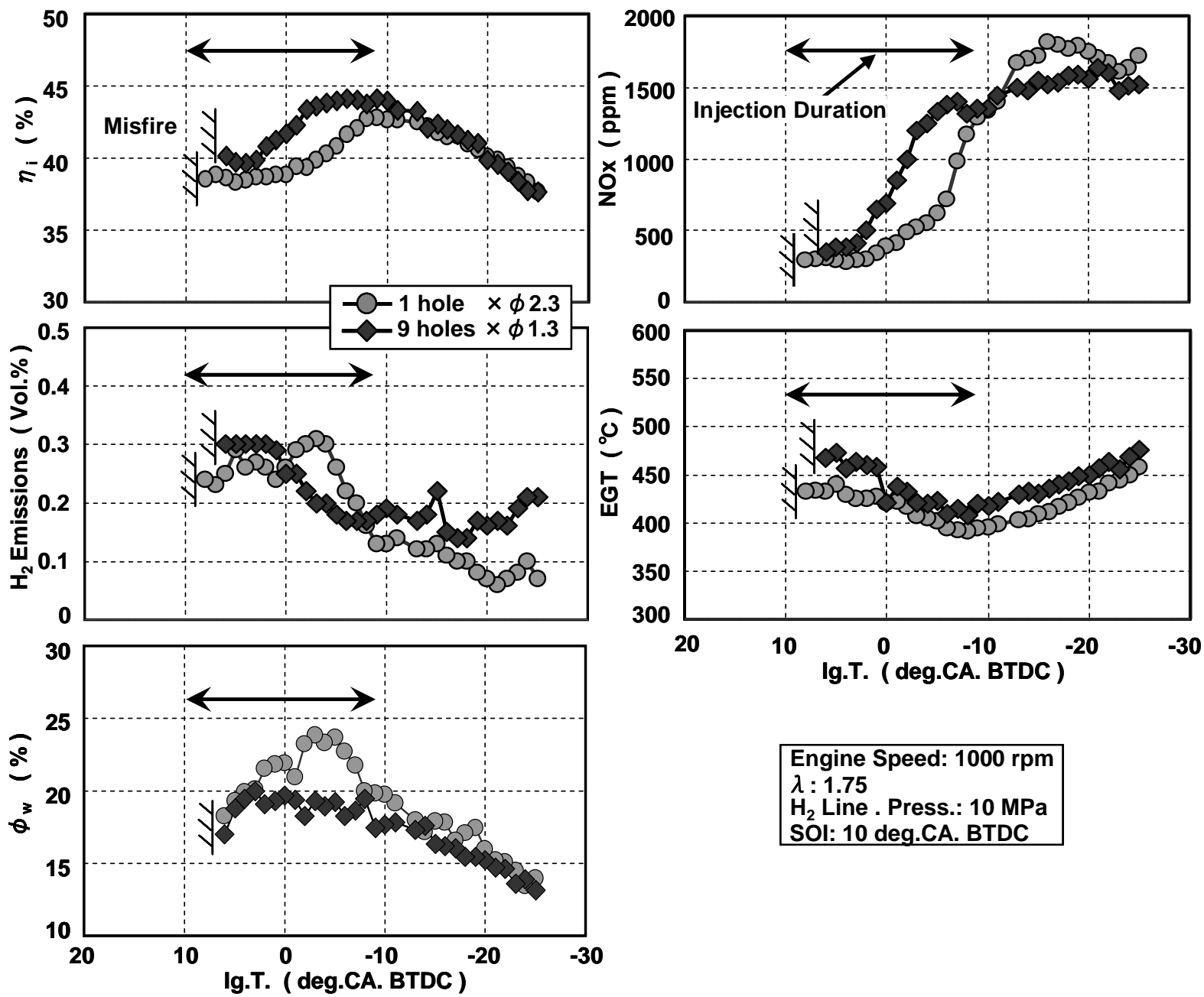

\begin{tabular}{|l|}
\hline Engine Speed: $1000 \mathrm{rpm}$ \\
$\lambda: 1.75$ \\
$\mathrm{H}_{2}$ Line . Press.: $10 \mathrm{MPa}$ \\
SOI: 10 deg.CA. BTDC \\
\hline
\end{tabular}

Fig. 5 Effect of ignition timing on engine performance for single-hole and multi-hole nozzles

especially setting the ignition timing close to the start of injection shows the potential for reducing NOx emissions by as much as another $80 \%$. This is attributed to ignition of a richer mixture plume than that ignited near the end of injection owing to the shortening of the mixing time of the hydrogen jet and air as the ignition timing is set closer to the start of injection.

The decline seen in thermal efficiency, on the other hand, is attributed to off-MBT ignition and an increase in the unburned hydrogen. The unburned hydrogen probably increased because the shortening of the time for air entrainment into mixture plume resulted in the formation of a richer mixture plume or because the local mixing of the fuel and air was insufficient. The increase seen in the exhaust gas temperature (EGT) as the ignition timing was advanced is attributed to the after-burning of the unburned hydrogen in the combustion chamber following the end of distinguish heat release. A comparison of the combustion characteristics for the single-hole and multi-hole nozzles shown in the figure indicates that the nine-hole nozzle showed less decline in thermal efficiency and also suppressed the increase in unburned hydrogen in the exhaust, though the effect on reducing NOx emissions was lower. These results indicated in the figure are attributed to the following effect of multi-hole nozzles.

(a) Increased air utilization caused by widely dispersed hydrogen plum in the combustion chamber increased thermal efficiency, but increased NOx formation.

(b) Enhansed air entrainment to the plume created by the increased surfece area reduced unburned hydrogen, but increased NOx formation. (c) Suppresed impingement of propagating flame to the combustion chamber caused by reduced jet velocity decreased cooling loss to the chamber wall. This detail will be shown by visualized flame propagation in the next section

Above results suggest that increased unburned hydrogen or decreased thermal efficiency which was the trade-offs of decreased NOx formation resulting from ignition during hydrogen injection can be mitigated by optimizing characteristics of the nozzle hole such as number and diameter, orientation of hole center, cross angle of holes and the others.

\subsubsection{Shadowgraph visualization of flame propagation for PCC combustion}

The shadowgraphic visualization experiment was carried out for ignition during the injection period and ignition after the end of injection for the 2.3-mm diameter single-hole nozzle and the multi-hole nozzle. The SOI was set at $10 \mathrm{deg}$. CA BTDC and excess air ratio is modified to $\lambda$ of 2.7 in visualization experiment. Shadowgraphic pictures were obtained at a rate of $15,000 \mathrm{fps}$. The ignition timing for the mid-inj.-ig. PCC was selected at 5 deg. CA BTDC, which is $5 \mathrm{deg}$. CA after the onset of injection. The ignition timing for the post-inj.-ig. PCC was selected at $-10 \mathrm{deg}$. CA BTDC, which is near the MBT timing.

(1) Ignition during the injection period (mid-inj.-ig. PCC)

As is shown in Fig. 6, the visualized results indicate that the hydrogen jet was burning immediately after ignition with the single-hole nozzle when the ignition timing was set during the 
(a) Ignition during the injection period ( Mid-Inj.-Ig. PCC )

Nozzle: $9 \times \phi 1.3$, SOI: 10 deg.CA BTDC, Ig.T.: 5 deg.CA. BTDC

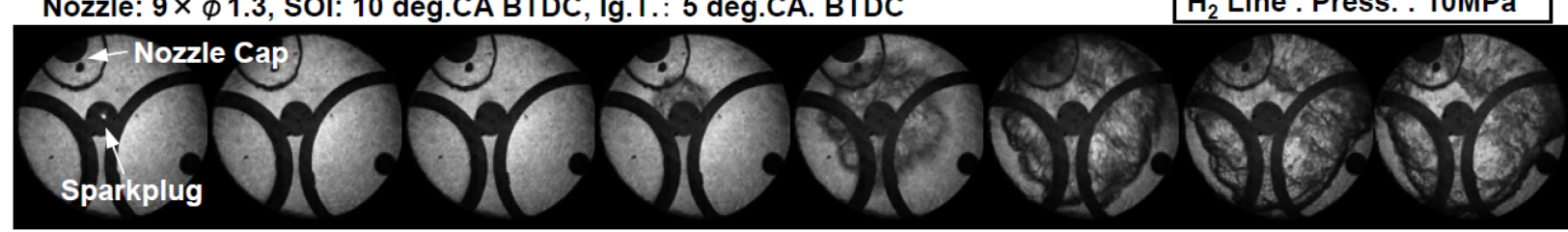

Nozzle : $1 \times \phi 2.3$, SOl:10 deg.CA BTDC, Ig.T.: 5 deg.CA. BTDC

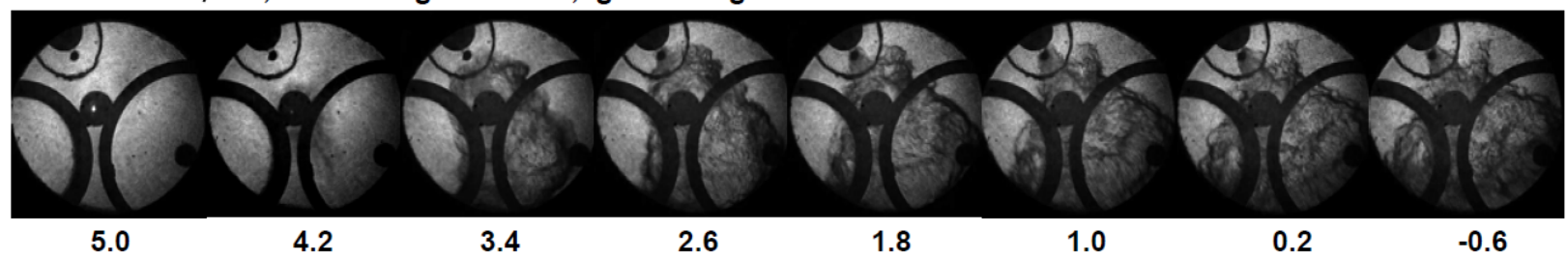

Crank Angle ( deg.CA. BTDC)

(b) Ignition after the end of injection (Post-Inj.-Ig. PCC)

Nozzle: $9 \times \phi 1.3$, sol:10 deg.CA BTDC, Ig.T.: -10 deg.CA. BTDC

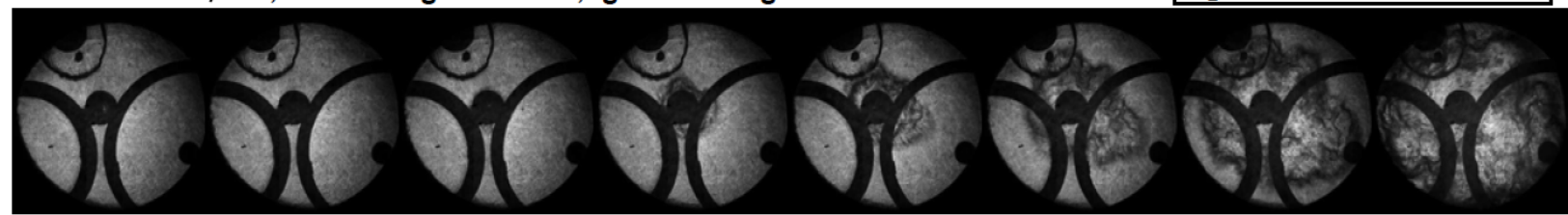

Nozzle: $1 \times \phi 2.3$, SOl:10 deg.CA BTDC, Ig.T.: -10 deg.CA. BTDC

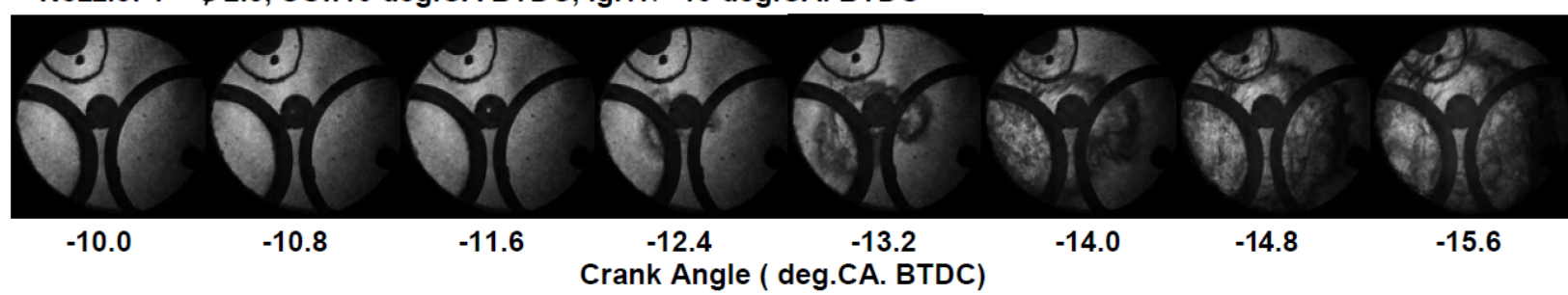

Fig. 6 Shadowgraphs of flame propagation relative to the ignition timing for single-hole and multi-hole nozzles

injection period. This combustion state is the proper regime for reducing NOx formation. With the multi-hole nozzle, it is observed that the flame spread in a circle-like pattern throughout the entire combustion chamber bowl, but the whole flame was positioned on the fuel injector side owing to the low flow velocity of the hydrogen jet. In contrast, the results for the single-hole nozzle show that the flame also impinged on the bowl wall owing to the effect of high velocity of the hydrogen jet.

Based on these results, there is concern that the cooling loss from the opposite wall of the piston bowl with the single-hole nozzle and that the cooling loss on the injector side might increase with the multi-hole nozzle. Accordingly, the results suggest that these respective issues observed for the injectors will have to be improved in order to improve combustion performance.

\section{(2) Ignition after the end of injection (post-inj.-ig. PCC)}

For MBT ignition after the completion of fuel injection, the results show that the flame propagated in almost like a circle pattern even with the single-hole nozzle without being influenced by the hydrogen jet configuration. This propagation behavior is attributed to the fact that the velocity of the hydrogen jet during injection was not sustained owing to the low density of the hydrogen and that the flow velocity of the jet was sharply attenuated upon the completion of injection. Consequently, the burning rate was markedly lower with this ignition timing compared with that for ignition during hydrogen injection. This issue will be discussed further in the following section. With the multi-hole nozzle, the flame also propagated in nearly a circle pattern.

As was seen in Fig. 5, NOx formation also increased to a corresponding extent with this ignition timing after the end of injection. Presumably, the mixing of the hydrogen and air proceeded at a corresponding pace and the influence of local flows originating in the hydrogen jet was lessened. It is inferred that this resulted in a mild combustion regime where the burning rate was not high.

\subsection{Effect of ignition timing on heat release of PCC combustion}

The heat release rates (HRR) of the 2.3-mm diameter singlehole nozzle and the multi-hole nozzle with nine $1.3-\mathrm{mm}$ diameter nozzle holes of data used in Fig. 5 are shown in Fig. 7. One inherent characteristic of PCC combustion is that the peak HRR is higher compared with that for early or late injection timings ${ }^{(7)}$. However, with the nine-hole injector used in the experiments to date, the peak HRR was found to be $0.2-0.3 \mathrm{~kJ} / \mathrm{deg}$ and did not vary much regardless of the ignition timing used. With the singlehole nozzle, on the other hand, the peak HRR was markedly higher for ignition during the latter stage of the injection period. The reasons for that can be understood as follows. The small nozzle hole diameter of this single-hole nozzle gives the hydrogen jet a high ejection velocity that enhances air entrainment by the 

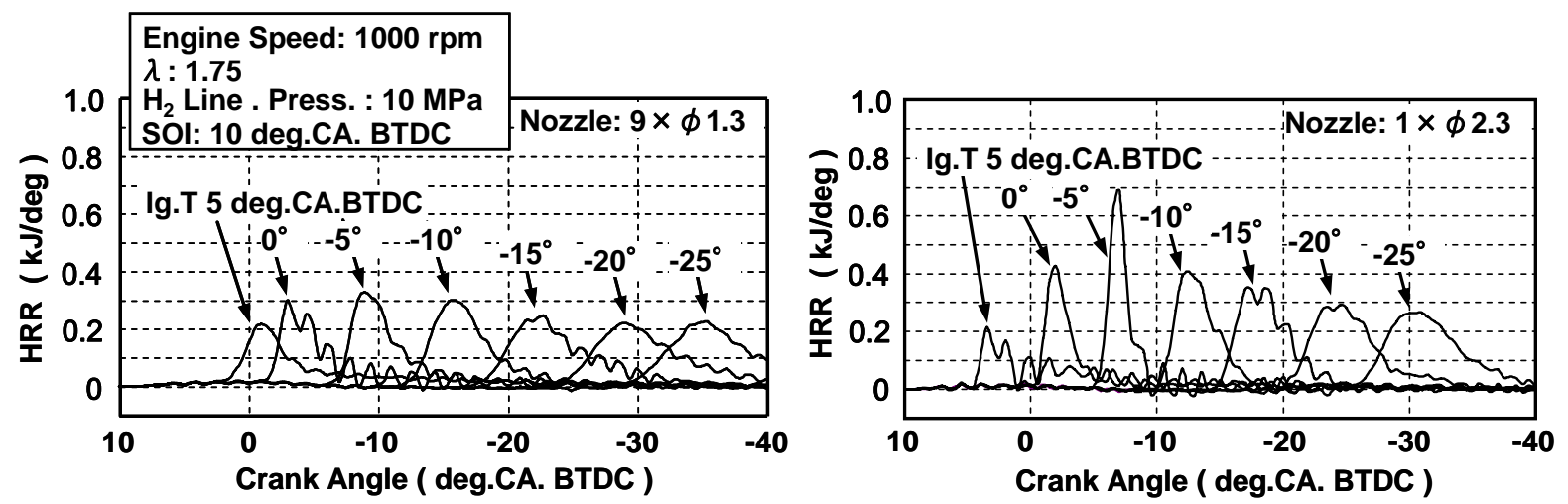

Fig.7 Heat release rates for various ignition timings with single-hole and multi-hole nozzles

hydrogen jet and promotes better mixture formation with the air, resulting in the formation of a lean mixture. In addition to that, the high ejection velocity produces strong turbulence (highly turbulent flow fields) in the hydrogen mixture plume and surrounding air, which results in highly turbulent combustion. Because the highly turbulent flow fields rapidly decay simultaneously with the end of injection, the HRR also drops sharply at the same time.

In the case of the multi-hole nozzle, the total hole crosssectional area is larger than that of the single-hole nozzle with a diameter of $2.3 \mathrm{~mm}$ used in the experiment. Consequently, high turbulent fields are not formed near the spark plug, which explains why a sharp rise in the HRR was not observed with the multi-hole injector.

The foregoing results imply that finding the best nozzle hole diameter will be an essential approach on optimization of the hydrogen jet and in devising ways of improving combustion characteristics further in the future as well as in moderating combustion such as by applying exhaust gas recirculation (EGR).

\section{Conclusion}

(1) It was shown that igniting the mixture right after the end of fuel injection named the post-injection-ignition-PCC can substantially reduce NOx emissions with minimizing decline in thermal efficiency in a direct-injection spark-ignition hydrogen engine under high-load operation.

(2) It was found that PCC is available igniting the plume even in the middle of fuel injection named the mid-injection-ignition PCC and has the potential to suppress NOx formation even further.

(3) The low NOx formation of the mid-inj.-ig. PCC is accomplished by igniting and burning the hydrogen jet during injection period while the level of air entrainment is low. The mid-inj.-ig. PCC uses the outstanding combustion characteristics of hydrogen, including its high burning velocity and wide combustible range especially on the rich mixture side. In addition, the high flow velocity of the hydrogen jet produces a field of strong turbulence in which the hydrogen fuel is burned quickly without any misfiring.

(4) At present, this research results indicate that igniting the hydrogen jet during the injection period has certain trade-offs, including a decline in thermal efficiency attributable to the increased unburned hydrogen and higher cooling loss. These characteristics have been made clear in studies using a singlehole nozzle with a simply shaped nozzle hole.

(5) These trade-offs include, for example, increased cooling loss caused by impingement of the flame on the opposite wall of the combustion chamber if jet velocity could not mitigated.
In future studies, plans to optimize the number of nozzle holes, the hole diameter and the other parameters are scheduled in order to overcome above mentioned issues and further improvement of the mid-inj.-ig. PCC process by attaining higher thermal efficiency will be expected.

\section{Acknowledgments}

The authors should like to express our grateful thanks to the members of Hydrogen Energy Research Center, Tokyo City University, especially Takamune Sakamono and Kouta Miura, who extended their kind assistance.

\section{References}

(1) Yasuo Takagi, et al. : R \& D of High Pressure Direct Injection Hydrogen Engine Systems, Journal of JSAE ( in Japanese ), Vol.39, No.5, p. 65-70 ( 2008 )

(2) Kaname Naganuma, et al. : Efficiency and EmissionsOptimized Operating Strategy of a High-pressure Direct Injection Hydrogen Engine for Heavy-duty Trucks, SAE Int. J. Engines 2(2), p. 132-140, doi: 10.4271/2009-01-2683 (2009).

(3) Thomas Wallner, et al. : Performance, Efficiency, and Emissions Evaluation of a Supercharged, Hydrogen-Powered, 4Cylinder Engine, SAE Paper 2007-01-0016, (2007).

(4) M.Shioji, et al. : Performance and Combustion Characteristics of a Direct-injection Hydrogen Engine, Journal of JSAE

( in Japanese ), Vol. 38, No.1, p. 109-114 ( 2008 )

(5) Sebastian Kaiser, et al. : PIV and PLIF to Evaluate Mixture Formation in a Direct-Injection Hydrogen-Fuelled Engine, SAE Paper 2008-01-1034, (2008).

(6) Victor M. Salazar, et al. : An Optical Study of Mixture Preparation in a Hydrogen-fueled Engine with Direct Injection Using Different Nozzle Designs, SAE Int. J. Engines March 2010 2, p.119-131

(7) Kaname Naganuma, et al. : Characteristics of low NOx formation of over-rich-mixture plume combustion in high pressure direct injection SI hydrogen engines, Journal of JSAE (in Japanese ), Vol. 41, No. 3, p. 685-690 ( 2010 )

(8) Masakuni Oikawa, et al. : Fundamental Characteristics of Ignition-Combustion of Rich Mixture Plume in High Pressure Direct Injection Hydrogen Engines, Journal of JSAE (in Japanese ), Vol.42, No.4, p.903-908 ( 2011 )

(9) Yusuke Ogasawara, et al., : Characteristics of Low NOx Formation of Over-Rich-Mixture Plume Combustion in High Pressure Direct Injection SI Hydrogen Engines (2st Report), Proceedings of 2010 JSAE Annual Congress ( in Japanese ), 
No. 29-10, p. 11-16, No. 20105375,( 2010 ).

(10) Kanan Sekine, et al. : Analytical Study on Hydrogen Jet Configuration and Flame Propagation by Shadowgraphic Visualization in High Pressure Direct Injection Hydrogen Engines, Proceedings of 2011 JSAE Annual Congress (in Japanese ), No. 156-11, p. 1-6, No. 20115652,( 2011 ). 